\title{
MusculoskeletalDisordersandTreatment
}

ORIGINAL RESEARCH

\section{Chemically Extracted Acellular Nerve Allograft Seeded with SDNF and Autogenic ADSCs for Peripheral Nerve Repairment in a Beagle Model}

\author{
Wei $\mathrm{Li}^{1 \#}$, Lei Chen ${ }^{1 \#}$, Dongqiang $\mathrm{Gu}^{1}$, Chunbao $\mathrm{Li}^{2}$ and Shunxin Zhang ${ }^{2 *}$ \\ ${ }^{1}$ Department of Orthopedics, Fourth Medical Center of PLA General Hospital, Beijing, China \\ ${ }^{2}$ Department of Ultrasound, 2nd Medical Center of PLA General Hospital, Beijing, China \\ ${ }^{\#}$ Equal Contribution
}

*Corresponding author: Shunxin Zhang, Department of Ultrasound, $2^{\text {nd }}$ Medical Center of PLA General Hospital, Beijing 100853, China

\begin{abstract}
Peripheral nerve repair is a major challenge in clinical practice. Nerve grafting is required to treat severe peripheral nerve defects caused by injuries. Available nerve sources for autologous transplantation are limited. Stem cells offer promise for peripheral nerve repair and regeneration. However, the current lack of Schwann cell phenotype, high costs, and major trauma limit the production of Schwann cells from stem cell differentiation. Thus, the purpose of this study is to investigate the ability of adipose-derived stem cells (ADSCs) to differentiate into the Schwann cell phenotype, after treatment with Schwann cell-derived neurotrophic factor (SDNF) in vitro. ADSCs were isolated and cultured for use in two types of nerve grafts: Acellular allogeneic nerves (ACEN), and acellular allogeneic nerves treated with SDNF (ACEN + SDNF). Chemically extracted, untreated acellular allogeneic nerves (CEN), acellular allogeneic nerves with isolated and cultured autologous SCs (CEN + SCs), and fresh autografts (AG) served as controls. Hematoxylin and eosin (HE) and S100 immunohistochemical staining were performed to observe the cytokine levels in the nerve grafts; enzyme-linked immunosorbent assay (ELISA) and realtime PCR were performed to evaluate the S100 and glial fibrillary acidic protein (GFAP) expression. The acellular nerve allografts seeded with ADSCs and SDNF showed significant S100 and GFAP expressions. No significant statistical differences were observed between the ACEN + SDNF, ACEN + SCs, and AG groups. These data suggest that such acellular nerve allografts should be evaluated as therapeutic strategies for treating severe peripheral nerve defects.
\end{abstract}

\author{
Keywords \\ Nerve regeneration, Peripheral nerve, Schwann cell, Nerve \\ graft, Adipose-derived stem cell, Cytokines
}

\section{Introduction}

If transection injuries of peripheral nerves are not surgically repaired, the patient can suffer from lifelong disability, pain, and impaired quality of life [1]. Treating severe peripheral nerve defects requires nerve grafting if the injuries are not directly repaired surgically. Most patients prefer the use of autologous nerve grafts to repair peripheral nerve defects, and autografts are recognized as the gold standard for nerve grafting [2]. However, available nerve sources for autologous transplantation are limited; additionally, autologous transplantation has limitations for clinical use because it results in the creation of a new nerve injury and the generation of donor site morbidity, and is associated with a long operative time [3]. Based on these limitations, allografts provide a readily accessible alternative strategy.

Nerve allografts have been used to overcome the limitations of autografts. A key factor for the use of nerve allografts not being effectively addressed yet is host immune rejection [4]. Experimental evidence has shown that peripheral nerve Schwann cells are the

Citation: Li W, Chen L, Gu D, Li C, Zhang S (2021) Chemically Extracted Acellular Nerve Allograft Seeded with SDNF and Autogenic ADSCs for Peripheral Nerve Repairment in a Beagle Model. J Musculoskelet Disord Treat 7:107. doi.org/10.23937/2572-3243.1510107

Accepted: December 23, 2021: Published: December 25, 2021

Copyright: (C) $2021 \mathrm{Li} \mathrm{W}$, et al. This is an open-access article distributed under the terms of the Creative Commons Attribution License, which permits unrestricted use, distribution, and reproduction in any medium, provided the original author and source are credited. 
main antigen-presenting cells [5], and previous studies have confirmed the immunogenicity of Schwann cells, which show transplant immune rejection [6,7]. Our previous study has shown that the immunogenicity of allogeneic nerve cells after chemical treatment is equal to that of autologous nerves and significantly lower than that of fresh nerve allografts; findings also confirmed the feasibility and safety of the chemical extraction of peripheral nerve cells [8].

However, for the repair of peripheral nerve injury, Schwann cells are the key for the migration of the axons to the distal end after transplantation [2,9]; they are also the main antigen-presenting cells of the allograft. Though no obvious immune rejections were observed among the chemically extracted acellular nerve allografts, the lack of Schwann cells and neurotrophic factors limits the nerve regeneration, restores the morphological structure of the damaged nerve, as well as promotes functional recovery. On the other hand, high costs and major trauma limit the application of autologous Schwann cells.

Peripheral nerve tissue engineering for cell replacement, especially using stem cells, has a potential biotherapeutic use for the treatment of peripheral nerve defects. Stem cells offer promise for peripheral nerve repair and regeneration. At present, the differentiation of stem cells to the target cells occurs mainly via the coculturing of the stem cells with the target cells. In this way, through signal transduction and interaction between the stem cells and target cells, it is possible to achieve the effect of induced differentiation $[10,11]$. However, the coculture method is relatively time-consuming, associated with high costs, and has the difficulties of small number of target cells being available and a diversity of phenotypes being generated after differentiation. In comparison with cell coculture, cytokines are easy to use and have a wide range of sources for their use in the differentiation of stem cells into Schwann cells. Although cytokines have a good prospect of application, only a few related studies have been performed.

Adipose-derived stem cells (ADSCS), which have the advantages of being easy to obtain and associated with low trauma, faster proliferation ability, and good stability, have been used in regeneration research. In 2001, Zuk, et al. isolated and cultured ADSCs from human adipose tissues [12]. Another study showed there was no obvious difference between ADSCs and bone marrow mesenchymal stem cells (BMSCs) with regards to surface labeling and multiple differentiation potential [13]. At present, in vivo or in vitro experiments have proved that ADSCs have the potential of multiple differentiation. Under certain conditions, ADSCs can be transformed into cartilage [14], bone [15], muscle [16], and other cell types. Using autologous ADSCs as seed cells for peripheral nerve tissue engineering has a good application prospect, given that the ADSCs differentiate into Schwann-like cells. However, in order to obtain a suitable number of cells, a relatively time-consuming, expensive, and in vitro coculture process with the risk of cell contamination and loss must be performed.

Studies have shown that cytokines [17] or environmental factors $[18,19]$ can induce ADSCs to differentiate into target cells. There are other important bioactive factors in the nervous system, and neurotrophic factors, including nerve growth factor (NGF), brainderived neurotrophic factor (BDNF), glial cell linederived neurotrophic factor (GDNF), and Schwann cellderived neurotrophic factor (SDNF), can induce stem cell differentiation. Numerous studies have confirmed that neurotrophic factors can accelerate axonal growth and restore nerve function, which is important for the repair of peripheral nerve injury [20-23]. SDNF is an active protein isolated from the cytoplasm of Schwann cells; it can markedly promote the regeneration of peripheral nerves. Because of its strong homology and good activity, it has great potential to induce stem cell differentiation. Compared to the other aforementioned neurotrophic factors, at present, studies about the use of SDNF to induce the differentiation of ADSCs into Schwann-like cells have rarely been reported, and the potential of this differentiation has not yet been explored. We tried to evaluate the potential of SDNF to induce the differentiation of ADSCs into Schwannlike cells, and transplanted the differentiated cells into the non-immunogenic chemically extracted acellular nerve allograft. Additionally, we also evaluated the phenotype and quantity of the differentiated cells and the morphology of the transplanted nerves in vitro and compared these parameters to those in the traditional coculture methods.

\section{Materials and Methods}

\section{Animals}

Four healthy 1-year-old male beagle dogs (weighing $10-10.5 \mathrm{~kg}$ ) were used. The animals were purchased from the Experimental Animal Center of PLA Navy General Hospital (Beijing, China). All animals were housed in a pathogen-free animal facility and maintained in accordance with the Committee on the Ethics of Animal Experiments and national guidelines on the care and use of laboratory animals. All surgical procedures and postoperative care methods were approved by the Institutional Animal Ethics Committee. The protocol was approved by the Committee on the Ethics of Animal Experiments at the PLA Navy General Hospital (2017-B031).

\section{Preparation of acellular nerve allografts}

Threebeagleswereanesthetized withmethoxyflurane (induction: $3 \%$ in $100 \% \mathrm{O}_{2}$; maintenance, $0.5-1 \%$ ). Onset of anesthesia was checked by the loss of the palpable 
reflex and pin-prick sensation over the corresponding operative areas. Surgery commenced within $10 \mathrm{~min}$ of the onset of anesthesia. The sciatic nerve, $6 \mathrm{~mm}$ in diameter and $5 \mathrm{~cm}$ long, was bilaterally harvested from the beagles. Using the improved Sondell method [24] for nerve chemical extraction, the nerves were subjected to a chemical extraction process, and then placed in sterile phosphate-buffered saline solution and stored at $4{ }^{\circ} \mathrm{C}$.

\section{Isolation and culture of autogenic ADSCs and SCs}

One beagle was anesthetized with methoxyflurane (induction: $3 \%$ in $100 \% \mathrm{O}_{2}$; maintenance, $0.5-1 \%$ ). Onset of anesthesia was checked by loss of the palpable reflex and pin-prick sensation over the corresponding operative areas. Surgery commenced within $10 \mathrm{~min}$ of the onset of anesthesia. ADSCs were obtained from beagle dog fat removed from the inguinal region. Meanwhile, the sciatic nerve, $6 \mathrm{~mm}$ in diameter and 5 $\mathrm{cm}$ long, was bilaterally harvested from the beagle. One of two nerves was placed in sterile phosphate-buffered saline solution and stored at $4{ }^{\circ} \mathrm{C}$ for the further use in the fresh autograft group. Fat tissues were diced into $1-\mathrm{mm}^{3}$ pieces and digested in $0.2 \%$ type I collagenase (Sigma-Aldrich, St. Louis, MO, USA) for $60 \mathrm{~min}$ at 37 ${ }^{\circ} \mathrm{C}$. Cells were cultured in $25-\mathrm{cm}^{2}$ cell culture flasks in a culture medium composed of equal parts of Dulbecco's modified Eagle medium and Ham's F-12 medium (DMEM/F12; HyClone, Utah, USA), 10\% fetal calf serum, and $1 \%$ penicillin/streptomycin until they attained confluence. The culture medium was changed every 3 days. ADSCs were analyzed by flow cytometry for the surface molecules CD34, CD45, CD73, and CD105. All ADSCs were used within the first three passages. A total of $2 \times 10^{5}$ ADSCs were obtained from the autogenic fat tissues. Another sciatic nerve was diced into $1-\mathrm{mm}^{3}$ pieces after stripping the epineurium. Then, the pieces were digested in $0.25 \%$ trypsin (Sigma-Aldrich, St. Louis, MO, USA) for $15 \mathrm{~min}$ at $37{ }^{\circ} \mathrm{C}$, and then, the serum culture solution was added to terminate the digestion. The supernatant was sucked out and then digested with $0.125 \%$ trypsin for 8 minutes. The two above steps were repeated to digest the nerve tissue completely. Cells were cultured in $25-\mathrm{cm}^{2}$ cell culture flasks in a culture medium composed of equal parts of Dulbecco's modified Eagle medium and Ham's F-12 medium (DMEM/F12; HyClone, Utah, USA), $10 \%$ fetal calf serum, and $1 \%$ penicillin/streptomycin until they attained confluence. The culture medium was changed every 3 days. The SCs were analyzed by flow cytometry for surface molecules S-100 and GFAP. All SCs were used within the first three passages. A total of $2 \times 10^{5} \mathrm{SCs}$ were obtained from the autogenic sciatic nerve.

\section{Cytokine treatments and groups}

To investigate the effect of SDNF, cultured ADSCS and SCs were divided into the following treatment groups ( $n=8$ per treatment group, in 6-cell culture clusters, the culture medium was changed every day): Acellular allogeneic nerve mixed with SDNF group (ACEN + SDNF, cell suspension of ADSCs was combined with the acellular allogeneic nerve and $100 \mathrm{ng} / \mathrm{ml}$ SDNF (BD Pharmingen, Franklin Lakes, NJ, USA)), and acellular allogeneic nerve group (ACEN, cell suspension of ADSCs was combined with the acellular allogeneic nerve, without SDNF). An acellular allogeneic nerve mixed with autologous isolated and cultured SCs group (CEN + SCS), chemically extracted acellular allogeneic nerve without any treatment group (CEN, $n=8)$, and a fresh autograft group $(A G, n=8)$ served as the controls.

\section{Assay of cell morphology and immunohistoche- mical staining}

To analyze the cell morphology after treatment with $100 \mathrm{ng} / \mathrm{ml} \mathrm{SDNF}$ for $14 \mathrm{~d}$, the culture supernatants of each group in 6-cell culture clusters were observed using an optical microscope (CX31, Olympus, JAPAN). At the same time, various nerve grafts were obtained, and $\mathrm{HE}$ and S100 immunohistochemical staining were performed to observe the number, distribution, and morphology of nerve cells in the groups.

\section{Quantitative assay of cytokines in the supernatant}

After treatment with cytokines for 7, 14, and 28 d, S100 and GFAP levels in the culture supernatants of each group were measured with enzyme-linked immunosorbent assay kits (ELISA Kit for S100 and GFAP, BD Pharmingen) for quantification. The detection sensitivity limit was at least $5 \mathrm{pg} / \mathrm{ml}$ for $\mathrm{S} 100$ and GFAP.

\section{Real-time PCR analysis}

To analyze the mRNA expression levels of S100 and GFAP, nerve grafts from each group were cut into pieces and placed in test tubes. Type II collagenase (3 $\mathrm{ml}, 0.2 \%$ ) (Sigma, St. Louis, MO, USA) was added to each tube. The stopper was put back on the tubes, which were then shaken. The sample was digested at $37^{\circ} \mathrm{C}$ for $4 \mathrm{~h}$ in an incubator under conditions of $5 \% \mathrm{CO}_{2}$. Phosphate-buffered saline (PBS) $(2 \mathrm{ml}$ ) containing $10 \%$ fetal bovine serum was added, and this mixture was stirred and maintained for $5 \mathrm{~min}$ at room temperature. The supernatant was removed carefully and placed in a $15-\mathrm{ml}$ centrifuge tube, and centrifuged at $1200 \mathrm{~g}$ at room temperature for $40 \mathrm{~s}$. The supernatant was carefully removed and placed an additional centrifuge tube, to which $5 \mathrm{ml}$ PBS was added. After stirring and centrifuging at $1200 \mathrm{~g}$ at room temperature for $5 \mathrm{~min}$, the supernatant was discarded. Trizol $(1 \mathrm{ml})$ was added to the centrifuge tube, followed by stirring. Then, using an RNeasy plus mini kit (Qiagen, Valencia, CA, USA), the total RNA from the samples of each treatment group after treatment with cytokines for $14 \mathrm{~d}$ was extracted. Genomic DNA was digested using an RNase-Free DNase kit (Qiagen). First-strand cDNA was synthesized using oligo-dT primers (Invitrogen, Carlsbad, CA, USA) and 


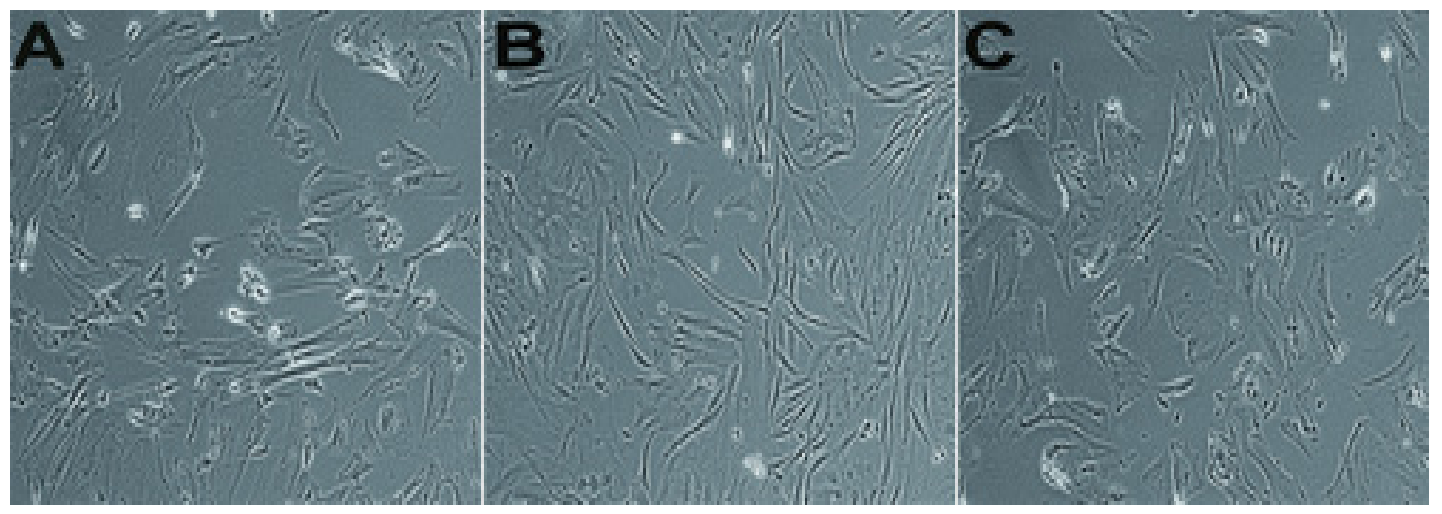

Figure 1: Culture supernatants were analyzed using an optical microscope $(\times 100)$. The number and biological morphology of the cells in the ACEN group are shown in Figure 1A, those of cells in the ACEN + SDNF group are shown in Figure 1B, and those of cells in the CEN + SCs group are shown in Figure 1C.

the Omniscript RT kit (Qiagen). The transcripts were quantified with real-time PCR using an ABI PRISM 7500 Sequence Detector (Applied Biosystems, Foster City, (A, USA), with Applied Biosystems predesigned TaqMan Gene Expression Assays (dog S100, Cf02661870_m1; dog GFAP, Cf02655694_m1) and reagents, according to the manufacturer's instructions. For relative quantification, gene expression in the samples was normalized to -actin mRNA expression (dog beta-actin, Cf03034055_u1), using the $2-\triangle \Delta C T$ method.

\section{Statistical analysis}

The data were analyzed using Stata 12.0 statistical software for single-factor ANOVA (Purchased from StataCorp, Texas, USA). Pairwise comparisons between each group were analyzed using the Bonferroni method, and the mean \pm SD was determined. $P<0.05$ was considered statistically significant.

\section{Results}

\section{Assay of cell morphology and immunohistochemical staining}

After treatment with SDNF for $14 \mathrm{~d}$, the culture supernatants of each group in 6-cell culture clusters were analyzed using an optical microscope (Figure 1). The results indicate that SDNF induces the ADSCs to differentiate into Schwann-like cells. The number and biological morphology of the cells in the ACEN + SDNF group (Figure 1B) were close to the level of those of autologous Schwann cells (Figure 1C), and were significantly better than those for the cells in the ACEN group (Figure 1A) without SDNF treatment. Similarly, HE staining and S100 immunohistochemical staining showed that the number, distribution, and morphology of positive cells in the ACEN + SDNF group (Figure 2B, Figure $2 \mathrm{E}$, Figure $2 \mathrm{H}$ and Figure $2 \mathrm{~K}$ ) were better than those in the ACEN group (Figure 2A, Figure 2D, Figure 2G and Figure $2 \mathrm{~J}$ ) and similar to the cocultured autologous Schwann cells (Figure 2C, Figure 2F, Figure $2 \mathrm{I}$ and Figure 2L).

\section{Quantitative assay of cytokines in the supernatant}

Using ELISA, we measured the S100 and GFAP levels in the cell culture supernatants in each treatment group after 7,14 , and $28 \mathrm{~d}$. These levels were compared to the levels seen in a fresh autograft. In the ACEN + SDNF group, S100 (Figure 3A) and GFAP (Figure 3B) levels were significantly higher after 7,14 and $28 \mathrm{~d}$, compared to the case for the ACEN and CEN groups. In contrast, there were no statistically significant differences between the S100 and GFAP expressions in the ACEN + SDNF, CEN + $\mathrm{SCs}$, and $\mathrm{AG}$ groups at all time-points.

\section{Quantitative analysis of mRNA expression}

mRNA transcript levels from each treatment group and the control groups were quantified by real-time PCR at the 14-d time-point (Figure 4A and Figure 4B). Compared to the case for the ACEN and CEN groups, the S100 and GFAP mRNA levels (2- $\Delta \Delta$ ct values) in the ACEN + SDNF group were significantly higher $(P<$ $0.01)$. In contrast, there were no statistically significant differences between the S100 and GFAP mRNA levels in the ACEN + SDNF, CEN + SCs, and AG groups.

\section{Discussion}

Nerve allografts have been used to overcome the limitations of autografts, but their use is impaired by host immune rejection. Based on immune rejection, there have been many researches about the methods for the treatment of removal of antigens in peripheral allogeneic nerve, such as using deep-frozen nerve grafts [25], freezing-drying nerve grafts [26], using frozenirradiated nerve grafts [27], and freezing-thawing nerve grafts [28]. They are more effective and simpler to use. However, their effects are also unreliable because Schwann cells and myelin sheaths cannot be removed throughout. The use of chemical extraction to treat allogeneic nerve grafts was a breakthrough [24].

Our previous research also showed that the use of chemical extraction to treat the cells significantly reduces antigenicity. Immunogenicity of the nerve allograft [8] or 


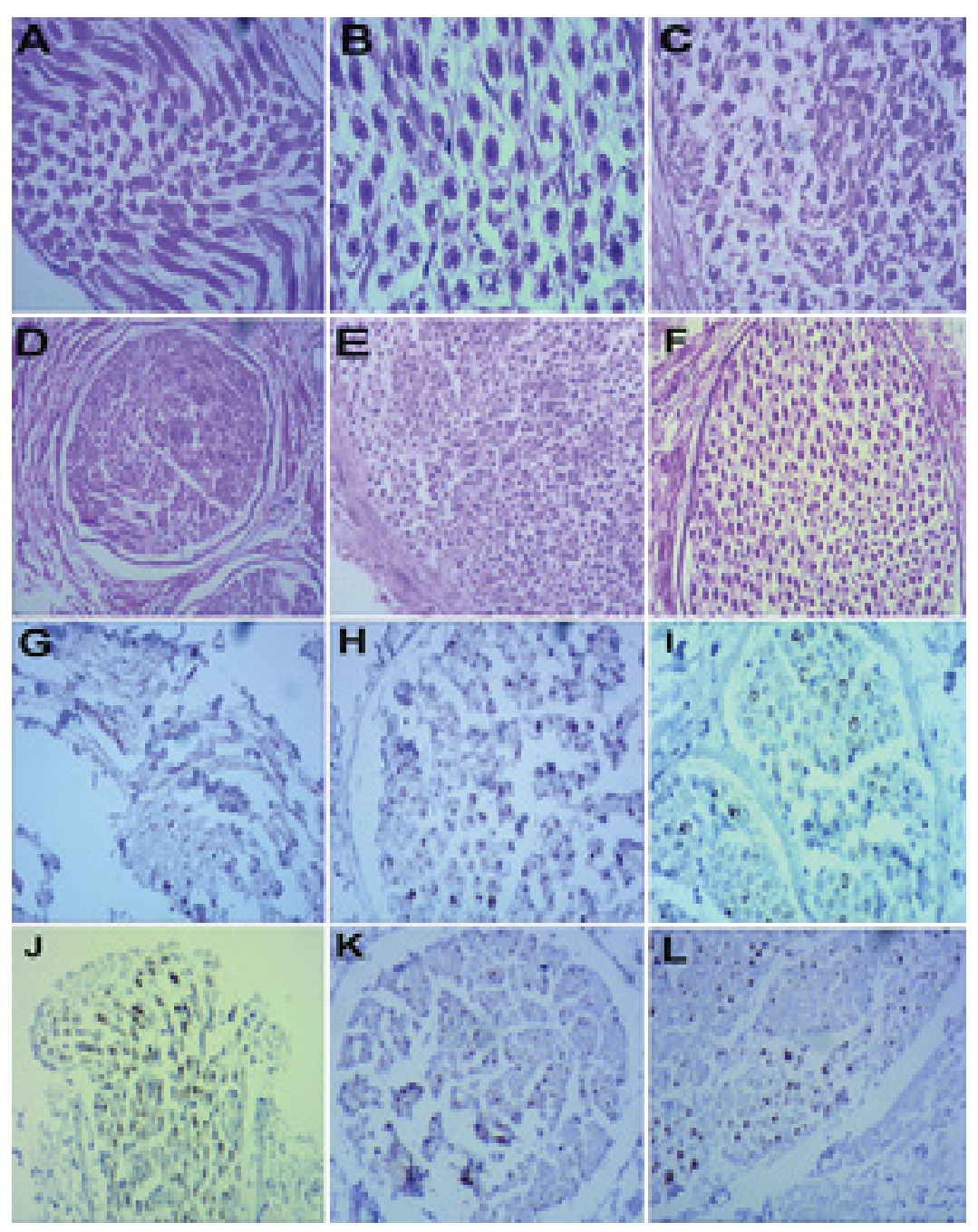

Figure 2: $\mathrm{HE}$ and $\mathrm{S} 100$ immunohistochemical staining of various nerve grafts (Figure $2 \mathrm{~A}, \mathrm{ACEN}$ group, HE, $\times 200$; Figure 2B, ACEN + SDNF group, HE, ×200; Figure 2C, CEN + SCs group, HE, ×200; Figure 2D, ACEN group, HE, ×100; Figure 2E, ACEN + SDNF group, HE, ×100; Figure 2F, CEN + SCs group, HE, ×100; Figure 2G, ACEN group, S100, ×200; Figure $2 \mathrm{H}$, ACEN + SDNF group, S100, ×200; Figure 2I, CEN + SCs group, S100, ×200; Figure 2J, ACEN group, S100, ×100; Figure 2K, ACEN + SDNF group, S100, ×100; Figure 2L, CEN + SCs group, S100, ×100).

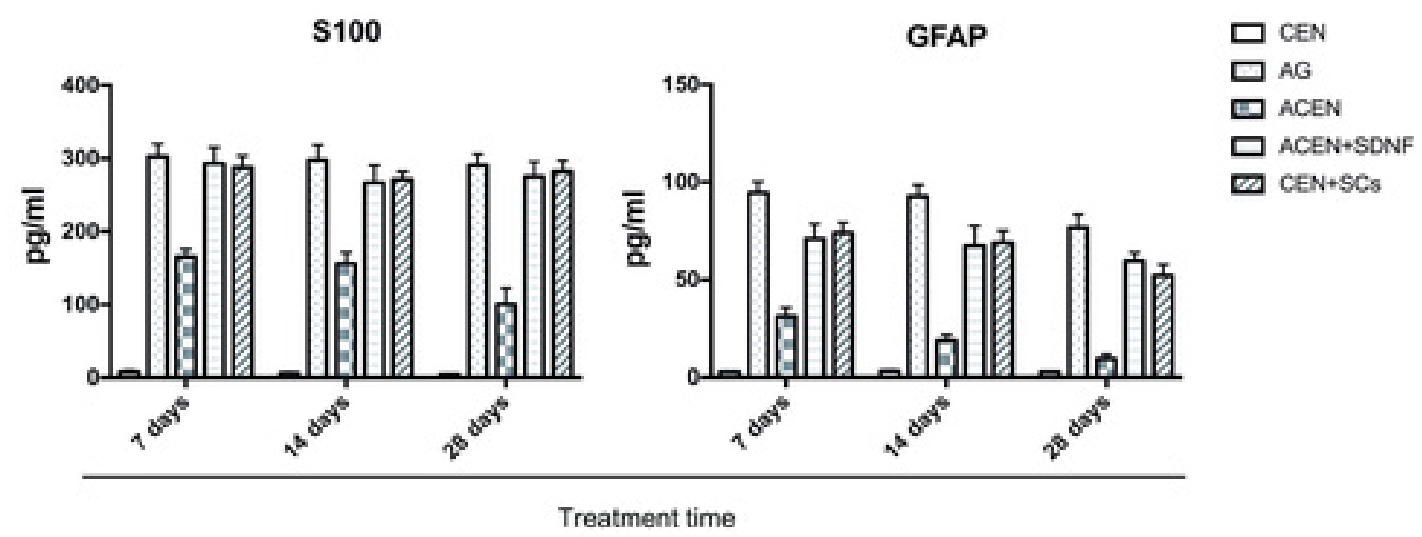

Figure 3: Quantitative expression of $\mathrm{S} 100$ and GFAP in supernatants. Cells in the ACEN + SDNF group were treated with SDNF for 7, 14, and $28 \mathrm{~d}$ in the culture medium before analysis. S100 (A) and GFAP (B) levels (pg/ml) in the ACEN + SDNF group (S100: $293.19 \pm 21.81,7$ d, 266.71 $\pm 25.50,14$ d, and 275.26 $\pm 20.25,28$ d; GFAP: $71.02 \pm 7.61,7$ d, $67.20 \pm 10.32$, $14 \mathrm{~d}$, and $59.77 \pm 4.12,28 \mathrm{~d})$ were significantly higher $(P<0.01)$ than the corresponding levels in the ACEN group (S100: $165.26 \pm 10.19,7 \mathrm{~d}, 155.96 \pm 15.33,14 \mathrm{~d}$, and 100.80 $\pm 21.23,28 \mathrm{~d} ; \mathrm{GFAP}: 31.21 \pm 4.67,7 \mathrm{~d}, 19.05 \pm 2.81,14 \mathrm{~d}$, and 9.62 $\pm 2.15,28 \mathrm{~d}$ ) and CEN group (S100: $7.21 \pm 2.02,7 \mathrm{~d}, 5.68 \pm 1.32,14 \mathrm{~d}$, and 3.79 $\pm 1.01,28 \mathrm{~d}$; GFAP: $2.59 \pm 0.32,7 \mathrm{~d}, 3.01 \pm$ $0.52,14 \mathrm{~d}$, and $2.64 \pm 0.23,28 \mathrm{~d}$ ) at 7,14 and $28 \mathrm{~d}$. There were no statistically significant differences between the S100 and GFAP expressions in the ACEN + SDNF, CEN + SCs, and AG groups at all three time-points. Pairwise comparisons between each group were carried out using the Bonferroni method, and the mean \pm SD was determined. $P<0.05$ was considered statistically significant. Data are presented as the means $\pm \mathrm{SD}$ of triplicate cultures. ${ }^{*} P<0.01$. 


\section{S100 expression}

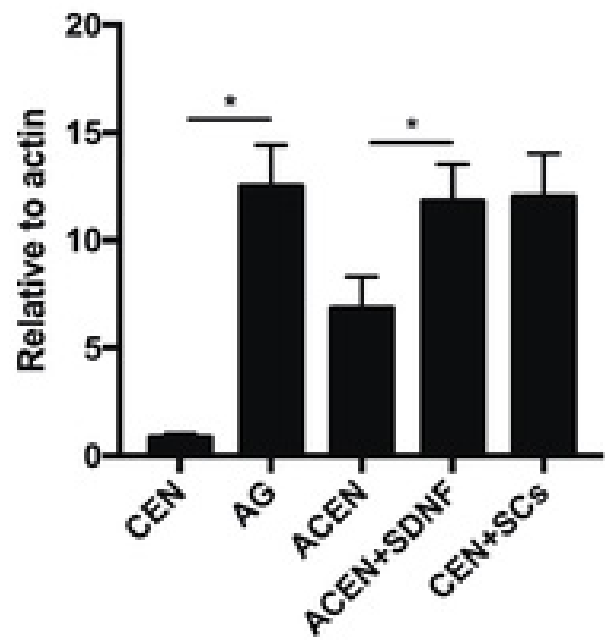

GFAP expression

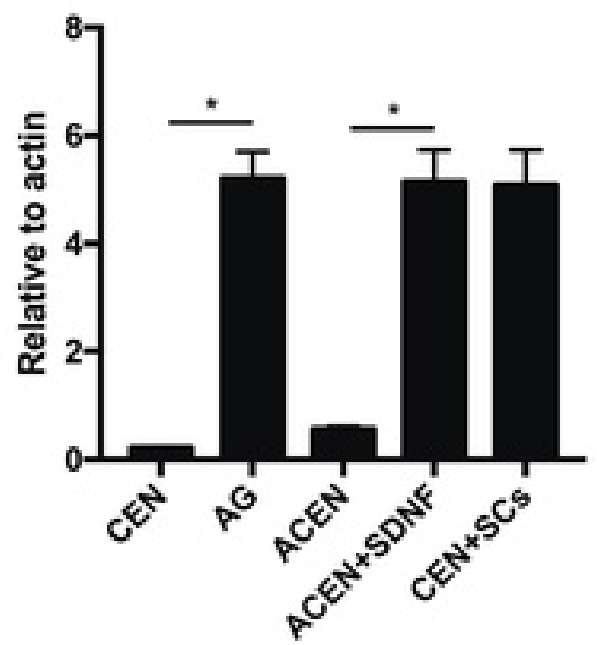

Figure 4: mRNA expressions of S100 and GFAP. Cells in the ACEN + SDNF group were treated with SDNF for $14 \mathrm{~d}$ in the culture medium before analysis. Total RNA was extracted and reverse transcribed to synthesize cDNA. The mRNA expressions for S100 (A) and GFAP (B) were quantified by real-time PCR, relative to the mRNA expression of the $\beta$-actin housekeeping gene. The data for mRNA expression are shown as $2-\Delta \Delta$ ct values. Compared to the ACEN group (S100: $6.82 \pm 1.48$; GFAP: $0.56 \pm 0.05$ ) and the CEN group (S100: $0.82 \pm 0.19$; GFAP: $0.21 \pm 0.02)$, the S100 and GFAP mRNA levels in the ACEN + SDNF group (S100: $11.82 \pm 1.71$; GFAP: $5.15 \pm 0.58$ ) were significantly higher $(P<0.01)$. There were no statistically significant differences between the S100 and GFAP mRNA levels in the ACEN + SDNF, CEN + SCs, and AG groups. Pairwise comparisons between each group were analyzed using the Bonferroni method and the mean \pm SD was determined. $P<0.05$ was considered statistically significant. Data are presented as the means \pm SD of triplicate cultures. ${ }^{*} P<0.01$.

xenograft [29] after the chemical extraction treatment is equal to or close to that of autologous nerves, and the main histocompatibility complex antigens within the aforementioned neural stem cells and the myelin sheath can be effectively removed, greatly reducing immunogenicity and preventing rejection. Schwann cells play key roles in the migration of the axon to the distal end after transplantation, and are the main host cells of the allogeneic immunization, which plays an "embarrassing" role in the repair of peripheral nerve injury. The source of autologous Schwann cells is the key point after the removal of antigens by nerve grafts; the availability of autologous Schwann cells is limited, because there is a creation of a new nerve injury. An alternative cell type, which can be easily isolated, cultured, and amplified in vitro, and can survive for a long time without immune rejection, must be obtained.

To this end, peripheral nerve tissue engineering is considered a promising treatment strategy. ADSCs are derived from the superficial adipose tissue of the human body, and have the advantages of being easy to obtain acquired in large amounts, and associated with the formation of only small wounds, a strong proliferation ability, and good stability. A method of coculturing ADSCs with Schwann cells was used to differentiate ADSCs into Schwann-like cells. However, in order to obtain a suitable number of cells, a relatively timeconsuming process that is associated with the risk of cell contamination and loss and the creation of a new nerve injury must be performed. Cytokines are convenient to obtain and use, and have no immunogenicity. SDNF is an active protein isolated from the cytoplasm of Schwann cells; it has a strong homology and good activity. However, studies on the use of SDNF have rarely been reported, and its potential of inducing differentiation has not yet been explored.

In our study, SDNF showed good compatibility with ADSCs and acellular nerve scaffolds in vitro, and SDNF could promote the differentiation of ADSCs into Schwann-like cells. After treatment with SDNF for $14 \mathrm{~d}$, we observed a spindle-type cell morphology, and the number and morphology of cells in the culture supernatants were found to be close to those of autologous Schwann cells; this was significantly better than the case for cells cultured without SDNF treatment.

In the ACEN + SDNF group, there was a cumulative effect of the levels of S100 and GFAP in the supernatant over time in culture. We believe this was due to the evaporation of the culture medium over time and the potential of SDNF to induce the differentiation of ADSCs into Schwann-like cells. S100 and GFAP levels in the supernatant were significantly higher from 7 to $28 \mathrm{~d}$. Although the secretion of S100 and GFAP slightly decreased at the 14-d time-point, no statistically significant difference between the $\mathrm{S} 100$ and GFAP expressions was seen in the ACEN + SDNF, CEN + SCs, and AG groups at all three time points. However, compared to the ACEN + SDNF group, the expressions of S100 and GFAP in ACEN group were significantly lower. Thus, based on the S100 and GFAP levels in the supernatant, SDNF showed the 
potential to induce the differentiation of ADSCs into Schwann-like cells.

Results from real-time PCR also showed that in contrast to the ACEN group, the mRNA expressions of S100 and GFAP in the ACEN + SDNF group were significantly higher. The major finding of this analysis is that after treatment with SDNF, the expressions of S100 and GFAP were enhanced; they were equal to or close to those observed in the CEN + SCs and AG groups.

\section{Conclusions}

In conclusion, treatment with SDNF significantly activated the differentiation of ADSCs into Schwann-like cells, and this activation was sustained. The acellularnerve allografts seeded with ADSCs and SDNF showed S100 and GFAP expressions. Thus, SDNF can be used as a cytokine for peripheral nerve tissue engineering. Additionally, it showed good compatibility with autogenic ADSCS and chemically extracted acellular nerve allografts. Thus, chemically extracted acellular nerve allografts seeded with SDNF and autogenic ADSCs have a potential biotherapuetic application for the treatment of severe peripheral nerve defects.

\section{Acknowledgments}

This study was supported by financial support from the National Science Foundation of China (81301033).

\section{Author Contributions}

Wei Li and Shunxin Zhang designed and directed the study, Wei Li, Lei Chen and Shunxin Zhang prepared chemically extracted acellular allogeneic nerves and performed the culturing of adipose-derived stem cells and Schwann cells. Wei Li and Lei Chen conducted the qRT-PCR and ELISA assays, and Shunxin Zhang conducted the HE and S100 immunohistochemical staining. Wei Li, Shunxin Zhang, Dongqiang $\mathrm{Gu}$ and Chunbao Li performed the animal treatments, and drafted the manuscript. All the authors have read and approved the final manuscript.

\section{Conflict of Interest}

The authors declare no conflict of interest.

\section{Availability of Data and Materials}

The authors declare all data and material availability.

\section{References}

1. IJpma FF, Nicolai JPA, Meek MF (2006) Sural nerve donorsite morbidity: Thirty-four years of follow-up. Ann Plast Surg 57: 391-395

2. Johnson EO, Zoubos AB, Soucacos PN (2005) Regeneration and repair of peripheral nerves. Injury 36 : S24-S29.

3. Galeano M, Manasseri B, Risitano, Geuna S, Scipio FD, et al. (2009) A free vein graft cap influences neuroma formation after nerve transection. Microsurgery 29: 568572.
4. Rovak JM, Bishop DK, Boxer LK, Wood SC, Mungara AK, et al. (2005) Peripheral nerve transplantation: The role of chemical acellularization in eliminating allograft antigenicity. J Reconstr Microsurg 21: 207-213.

5. Hayry P, Renkonen R, Leszczynski D, Mattila P, Tiisala S, et al. (1989) Local events in graft rejection. Transplant Proc 21: 3716-3720.

6. Aguayo AJ, Bray GM, Kasarjian J (1978) Differences in myelination of mouse axons by transplanted human and mouse Schwann cells. Neurology 28: 356.

7. Aguayo AJ, Bray GM, Perkins SC (1979) Axon-Schwann cell relationships in neuropathies of mutant mice. Ann NY Acad Sci 317: 512-531.

8. Li W, Wu WW, Lin XS, Hou SX, Zhong HB, et al. (2012) Changes in $T$ lymphocyte subsets and intracellular cytokines after transfer of chemically extracted acellular nerve allografts. Mol Med Rep 5: 1080-1086.

9. De Ruiter GC, Malessy MJA, Yaszemski MJ, Windebank AJ, Spinner RJ (2009) Designing ideal conduits for peripheral nerve repair. Neurosurg Focus 26: E5.

10. Purmessur D, Schek RM, Abbott RD, Ballif BA, Godburn $\mathrm{KE}$, et al. (2011) Notochordal conditioned media from tissue increases proteoglycan accumulation and promotes a healthy nucleus pulposus phenotype in human mesenchymal stem cells. Arthritis Res Ther 13: 81.

11. Ruan D, Zhang Y, Wang D, Zhang C, Wu J, et al. (2012) Differentiation of human Wharton's jelly cells toward nucleus pulposus-like cells after coculture with nucleus pulposus cells in vitro. Tissue Eng Part A 18: 167-175.

12. Zuk PA, Zhu M, Ashjian P, De Ugarte DA, Huang JI, et al. (2002) Human adipose tissue is a source of multipotent stem cells. Mol Biol Cell 13: 4279-4295.

13. De Ugarte DA, Alfonso Z, Zuk PA, Elbarbary A, Zhu M, et al. (2003) Differential expression of stem cell mobilizationassociated molecules on multi-lineage cells from adipose tissue and bone marrow. Immunol Lett 89: 267-270.

14. Erickson GR, Gimble JM, Franklin DM, Rice HE, Awad $\mathrm{H}$, et al. (2002) Chondrogenic potential of adipose tissuederived stromal cells in vitro and in vivo. Biochem Biophys Res Commun 290: 763-769.

15. Conejero JA, Lee JA, Parrett BM, Terry M, Wear-Maggitti $\mathrm{K}$, et al. (2006) Repair of palatal bone defects using osteogenically differentiated fat-derived stem cells. Plast Reconstr Surg 117: 857-863.

16. Bacou F, el Andalousi RB, Daussin PA, Micallef JP, Levin JM, et al. (2004) Transplantation of adipose tissue-derived stromal cells increases mass and functional capacity of damaged skeletal muscle. Cell Transplant 13: 103-111.

17. Yang Z, Huang CYC, Candiotti KA, Zeng X, Yuan T, et al. (2011) Sox-9 facilitates differentiation of adipose tissuederived stem cells into a chondrocyte-like phenotype in vitro. J Orthop Res 29: 1291-1297.

18. Gruber HE, Deepe R, Hoelscher GL, Ingram JA, Norton HJ, et al. (2010) Human adipose-derived mesenchymal stem cells: Direction to a phenotype sharing similarities with the disc, gene expression profiling, and coculture with human annulus cells. Tissue Eng Part A 16: 2843-2860.

19. Choi EH, Park H, Park KS, Park KS, Kim BS, et al. (2011) Effect of nucleus pulposus cells having different phenotypes on chondrogenic differentiation of adipose-derived stromal cells in a coculture system using porous membranes. Tissue Eng Part A 17: 2445-2451. 
20. Lykissas MG, Batistatou AK, Charalabopoulos KA, Beris $A E$ (2007) The role of neurotrophins in axonal growth, guidance, and regeneration. Curr Neurovasc Res 4: 143151.

21. Matsumoto T, Rauskolb S, Polack M, Klose J, Kolbeck R, et al. (2008) Biosynthesis and processing of endogenous BDNF: CNS neurons store and secrete BDNF, not proBDNF. Nat Neurosci 11: 131-133.

22. Martinowich K, Manji H, Lu B (2007) New insights into BDNF function in depression and anxiety. Nat Neurosci 10 1089-1093.

23. Wood MD, Moore AM, Hunter DA, Tuffaha S, Borschel $\mathrm{GH}$, et al. (2009) Affinity-based release of glial-derived neurotrophic factor from fibrin matrices enhances sciatic nerve regeneration. Acta Biomater 5: 959-968.

24. Sondell M, Lundborg G, Kanje M (1998) Regeneration of the rat sciatic nerve into allografts made acellular through chemical extraction. Brain Res 795: 44-54.
25. Chaĭkovskiĭ lu B, Zurnadzhi lu N (1988) Ultrastructure of a sciatic nerve allograft preserved at an ultralow temperature. Arkh Anat Gistol Embriol 95: 17-21.

26. Taniguchi M (1990) An experimental study on regeneration of the inferior alveolar nerve after lyophilized nerve homografting in the rabbit. Shikwa Gakuho 90: 1057-1076.

27. Mackinnon SE, Hudson AR, Falk RE, Kline D, Hunter D (1984) Peripheral nerve allograft: An immunological assessment of pretreatment methods. Neurosurgery 14: 167-171.

28. Sketelj J, Bresjanac M, Popović M (1989) Rapid growth of regenerating axons across the segments of sciatic nerve devoid of Schwann cells. J Neurosci Res 24: 153-162.

29. Li W, Jia Z, Zhang S, Lin X, Yang R, et al. (2013) The cellular immune mechanism after transfer of chemically extracted acellular nerve xenografts. PLoS One 8: e68806. 